\title{
EVALUATION OF PAEDIATRIC HEAD TRAUMA PATIENTS WITH COMPUTED TOMOGRAPHY; THE REQUIREMENT OF COMPUTED TOMOGRAPHY IN CHILDREN WITH HEAD INJURY: A CROSS-SECTIONAL STUDY
}

\author{
Sema Avcl ${ }^{\oplus}$, Bulut Demirel ${ }^{2} \odot$, Lukasz Szarpak ${ }^{3,4,5} \odot$, Eren Usul ${ }^{6} \oplus$, Bülent Güngörer ${ }^{7} \oplus$ \\ ${ }^{1}$ Department of Emergency Medicine, Faculty of Medicine, Amasya University, Amasya, Turkey \\ ${ }^{2}$ Department of Emergency Medicine, Halil Şıvgın Çubuk State Hospital, Ankara, Turkey \\ ${ }^{3}$ Polish Society of Disaster Medicine, Warsaw, Poland \\ ${ }^{4}$ Bialystok Oncology Center, Bialystok, Poland \\ ${ }^{5}$ Maria Sklodowska-Curie Medical Academy in Warsaw, Poland \\ ${ }^{6}$ Dr Nafiz Körez Sincan State Hospital, Ankara, Turkey \\ ${ }^{7}$ Interventional Radiology Department Ankara City Hospital, Ankara, Turkey
}

\begin{abstract}
INTRODUCTION: In this study, we aimed to reveal the cranial computed tomography (CT) results of paediatric head trauma cases taken in our hospital and what clinical variables might be related to pathology in cranial CT.
\end{abstract}

MATERIAL AND METHODS: Age, gender, glasgow coma scale (GCS), open or suspicious skull fracture, vomiting $\geq 2$, retrograde amnesia $\geq 30$ minutes, the detailed mechanism of injury and CT findings (if CT is available) were evaluated.

RESULTS: 66 of the cases were female (35.7\%) and 119 were male (64.7\%). The ages of the patients vary between 0 and 16 and the average age is $6.76 .108(58.4 \%)$ of the patients had admitted to the hospital with traumas resulted from falling. $33(17.8 \%)$ of them were passengers of a four-wheeled vehicle and $15(8.1 \%)$ were had been crashed with a four-wheeled vehicle.

CONCLUSIONS: In paediatric head traumas, falls and traffic accidents are in the first place and the measures taken in this regard should be increased.

KEY WORDS: head trauma, CT scan, pediatric trauma

Disaster Emerg Med J 2021; 6(1): 21-25

\section{INTRODUCTION}

Paediatric head injuries are still important today. It is one of the highest causes of mortality and morbidity in paediatric traumas and seen commonly despite the use of special facilities with developing technologies for children such as special playgrounds, protective equipment against potential domicile accidents, and child safety seats providing the least damage during a traffic accident [1, 2]. Especially, in underdeveloped and developing countries, traumas are among the leading causes of death among the young population and more than half of these deaths result from head traumas [3]. In severe cases, head traumas with mortality up to $70 \%$ have been reported as 
150-200/100.000 between 1 and 14 years old, and $550 / 100.000$ in the 15-24 age group. Most of these head traumas (89.1\%) are minor head traumas [4-6].

Computed tomography (CT) is recommended as the first imaging method to be performed in patients with severe head injuries without discrimination of children or adults [1]. In minor head traumas, it is recommended only in the selected patient group due to its cost and high dose radiation exposure [2, 7]. In the group of patients with minor head trau$\mathrm{ma}$, the rate of detection of pathological findings in cranial CT is between $4-8 \%$, and only a small part of these pathologies results in mortality. However, despite these scientific explanations, physicians keep the cranial $C T$ imaging threshold recommended in the guides low due to fear of malpractice, unwillingness to take a risk and easy accessibility $[8,9]$.

In this study, we aimed to reveal the cranial CT results of paediatric head trauma cases taken in our hospital and what clinical variables might be related to pathology in cranial CT. We gathered all the findings under a single roof, as malpractice cases may exist even in the mildest and the least life-threatening pathologies seen in cranial CTs.

\section{MATERIAL AND METHODS}

The medical records of 185 paediatric patients who were 16 years of age or younger with head traumas admitted to a secondary care center from June 2016 to December 2016, were assessed. Age, gender, glasgow coma scale (GCS), open or suspicious skull fracture, vomiting $\geq 2$, retrograde amnesia $\geq 30$ minutes, the detailed mechanism of injury and $C T$ findings (if $C T$ is available) were evaluated. All head CT scans were performed based on the combined decision reached by at least one general practitioner and one emergency specialist in the ER. This study was approved by the institutional ethics committee, which waived informed consent owing to the retrospective study design.

All statistical calculations were performed with SPSS 23.0 (SPSS for Windows, Chicago, IL, $\mathrm{SA})$. The continuous variables were expressed as mean \pm standard deviation and the categoric variables were defined as percentages (\%).

\section{RESULTS}

Our study included 185 paediatric head trauma patients admitted to our hospital on the specified

Table 1. Injury mechanisms of the patients
\begin{tabular}{|l|c|c|}
\hline & Frequency & Percent \\
\hline Driver in motor vehicle (4 wheels) & 1 & 0.5 \\
\hline Occupant in motor vehicle (4 wheels) & 33 & 17.8 \\
\hline $\begin{array}{l}\text { Pedestrian stuck by motor vehicle } \\
\text { (4 wheels) }\end{array}$ & 15 & 8.1 \\
\hline $\begin{array}{l}\text { Pedestrian struck by motorcycle } \\
\text { (2-3 wheels) }\end{array}$ & 2 & 1.1 \\
\hline Fall accident & 108 & 58.4 \\
\hline Assault (by fist, push or shake) & 7 & 3.8 \\
\hline Assault by hard object & 6 & 3.2 \\
\hline Hard object fallen onto head & 3 & 1.6 \\
\hline Head crash onto hard object & 6 & 3.2 \\
\hline Animal attack & 4 & 2.2 \\
\hline
\end{tabular}

Table 2. GCS scores and pathological findings ratio
in CT scan
\begin{tabular}{|l|c|c|}
\hline & $\begin{array}{c}\text { CT scan + for } \\
\text { pathological finding }\end{array}$ & $\begin{array}{c}\text { CT scan - for } \\
\text { pathological finding }\end{array}$ \\
\hline GCS 15 & $60(33 \%)$ & $102(67 \%)$ \\
\hline GCS $13-14$ & $11(100 \%)$ & $0(0 \%)$ \\
\hline GCS $<13$ & $12(100 \%)$ & $0(0 \%)$ \\
\hline
\end{tabular}

CT — computed tomography; GCS — glasgow coma scale

dates. Of these patients, 66 were female (35.7\%) and 119 were male $(64.7 \%)$. The ages of the patients vary between 0 and 16 and the average age is 6.76 (standard deviation is 4.359).

Of those patients, 108 (58.4\%) had admitted to the hospital with traumas resulted from falling. $33(17.8 \%)$ of them were passengers of a fourwheeled vehicle and 15 (8.1\%) were had been crashed with a four-wheeled vehicle. Those were the most frequent three reasons of hospitalization. Injury mechanisms of the patients are classified in Table 1.

Pathology was detected in cranial CT in all ( $n=23)$ paediatric head trauma patients with Glasgow Coma Scale 14 and below. In the patients that GSK was evaluated as 15 , the rate of detection of pathological findings was GKS 13-14 and was found to be significantly lower than those with and GKS $<13(p<0.001)$. However, in $33 \%$ of patients evaluated clinically as GKS 15, appearance pathological findings in cranial $C T$ is a point that should be emphasized (Table 2).

In all of the patients with open skull injuries (n-2), vomiting (n-17) and suspected skull fracture (n-8), 


Table 3. Clinical findings and CT imaging rates of the patients
\begin{tabular}{|l|c|c|c|}
\hline & CT (+) & CT (-) & P value \\
\hline $\begin{array}{l}\text { Open skull fracture } \\
(-)\end{array}$ & $81(44.3 \%)$ & $102(55.7 \%)$ & 0.200 \\
$(+)$ & $2(100 \%)$ & - & $<0.001$ \\
\hline $\begin{array}{l}\text { Vomiting } \\
(-)\end{array}$ & $66(39.3 \%)$ & $102(60.7 \%)$ & 0.001 \\
$(+)$ & $17(100 \%)$ & - & \\
\hline $\begin{array}{l}\text { Suspicious skull fracture } \\
(-)\end{array}$ & $75(42.4 \%)$ & $102(57.2 \%)$ & \\
$(+)$ & $8(100 \%)$ & - & $<0.001$ \\
\hline $\begin{array}{l}\text { Retrograde amnesia }>30 \text { min } \\
(-)\end{array}$ & $55(35.5 \%)$ & $100(64.5 \%)$ & $2(6.7 \%)$ \\
$(+)$ & $28(93.3 \%)$ & & \\
\hline
\end{tabular}

CT - computed tomography

pathological findings in cranial CT was detected. However, in open skull injuries, there was no statistical difference between the patients with pathology on cranial $C T$ and the group without detection ( $p: 0.2)$. There is a statistical difference between patients with vomiting and suspected skull fracture and patients with pathology in cranial $\mathrm{CT}$ and those not detected ( $p ;<0.001$ and 0.001 , respectively). In patients with vomiting and suspected skull fracture, there is a statistical difference between patients with and without pathology in cranial CT $(p ;<0.001$ and 0.001 , respectively). Retrograde amnesia was detected in 30 patients and 28 (93.3\%) of these patients had pathological findings on cranial CT and there was a statistical difference between both groups $(p ;<0.001)$. In addition, when retrograde amnesia is evaluated with other findings, the rate of vomiting was found to be higher in patients with retrograde amnesia $(p=0.03)$.

Clinical findings and $C T$ imaging rates of the patients are presented in Table 3.

When patients were separated by two age limits, the rate of pathological findings in cranial $\mathrm{CT}$ was found to be similar between those below 2 years old and those above.

\section{DISCUSSION}

In the world also by including the developed countries, traumas are one of the most common causes of mortality and morbidity [10]. Among traumas, the head trauma is only itself responsible for $1 / 3$ of mortalities. In our study, in the children with the head trauma, the ratio of the boys to the girls was found to be $1.8 / 1$. This rate is lower than that of adults which were observed as 2.49/1-2.57/1 [11]. Boys are more active and keen on dangerous games and activities compared to the girls, which can explain this difference. The growing gap of the difference in the advanced age period is explained by a more active lifestyle, more work in the heavy industry due to industrialization and more presence in an open environment [11]. The most common complaint among our patients is a motor vehicle accident and falling. Admission reasons of our patients show similarity to the cases in the literature [12]. However, assault, which takes the third place as the cause of head traumas in adults, forms a very small part in paediatric head trauma [13]. This is because assault is more frequently seen in the adult patient group. The fight in the paediatric patient group is generally seen as pushing. It is common for patients with open skulls to have pathology in cranial CT. In the presence of a visible cranial pathology, cranial CT imagining is to investigate the presence of another pathology that is not visible below $[14,15]$. We think that there does not exist any difference between the patients that pathological findings were observed or not in the cranial CT statistically because this pathology was rarely observed in our patient group. In terms of head trauma, vomiting is an important finding and stimulates the clinician. In imaging guidelines for head traumas, vomiting depending on the number or not is considered an indication (16-18). In the study in which 19.920 paediatric patients were analysed, including studies examining paediatric head traumas such as PECARN, CATCH and CHALICE CDRs, vomiting showed the possibility of pathology detection in CT imaging around $44 \%[17,19,20]$. The reason of being so high in our study is that vomiting was ob- 
served in the severe cases. Another explanation may be that nausea and vomiting in patients with minor head traumas were neglected. Amnesia finding is a finding that indicates the presence of pathology in patients with head trauma and is seen only itself in moderate-risk patients. Retrograde amnesia is important because it decreases the reliability in the patient's history of trauma and can also be a finding of brain damage and constitutes an indication for cranial CT imagining [21]. In our study, pathology was found in cranial $C T$ in most of the patients with retrograde amnesia. This is compatible with the studies in the literature and the recommendations of the guidelines and supports cranial CT imagining in children having head trauma with retrograde amnesia alone itself [21]. Vomiting in patients with retrograde amnesia is statistically significant and normal for two findings of head trauma accompany each other. The clinician's suspicion following the anamnesis and the examination is a result of his experience, and this suspicion helps to diagnose many diseases. Findings such as a battle sign, raccoon eye or hemotympanum in head traumas have been shown to be related with a skull base fracture in the literature [14, 22]. Apart from this, physical examination findings such as staging of the skull are especially important in suspicion of abuse [22]. Pathology is an important result in cranial CTs taken in paediatric patients in head traumas, which are considered to be suspicious skull fractures after anamnesis and examination by physicians. The importance of taking amnesia and acquiring examination skills in the training of physicians has been demonstrated with this study. The detection of pathology in cranial $C T$ results after head trauma in the age group under two years and above made us think that physicians should be vigilant in two issues [23]. First of all, the symptoms and findings of children under 2 years of age, who cannot speak or express themselves, should not be ignored or underestimated $[21,24]$. Secondly, if cranial CT imagining is not or cannot be performed in children under two years old, the family should be informed in the most appropriate way and emergencies should be explained. Otherwise, both the increasing number of unnecessary hospital applications and malpractice cases are inevitable [12].

\section{CONCLUSIONS}

In paediatric head traumas, falls and traffic accidents are in the first place and the measures taken in this regard should be increased. There are many guidelines used in paediatric head traumas, and findings such as low GKS, retrograde amnesia, vomiting, suspicious skull fracture and open skull are important. Attention should be paid to the signs and symptoms in children under 2 years old and physicians should be trained in anamnesis-examination.

\section{REFERENCES}

1. Tang PH, Lim CC. Imaging of accidental paediatric head trauma. Pediatr Radiol. 2009; 39(5): 438-446, doi: 10.1007/s00247-008-1083-7, indexed in Pubmed: 19125244.

2. Er A, Akman C, Alatas I, et al. Should Children with Minor Head Injury Routinely Have CT Scan? Jinekoloji Obstetrik Pediatri ve Pediatrik Cerrahi Dergisi. 2013; 5(3): 131-135, doi: 10.5222/jopp.2013.131.

3. IŞIK H. Retrospective analysis of 954 adult patients with head injury: an epidemiological study. Turkish Journal of Trauma and Emergency Surgery. 2011; 17(1): 46-50, doi: 10.5505/tjtes.2011.57431.

4. Ro YS, Shin SDo, Holmes JF, et al. Traumatic Brain Injury Research Network of Korea (TBI Network). Comparison of clinical performance of cranial computed tomography rules in patients with minor head injury: a multicenter prospective study. Acad Emerg Med. 2011; 18(6): 597-604, doi: 10.1111/j.1553-2712.2011.01094.x, indexed in Pubmed: 21676057.

5. Culotta VP, Sementilli ME, Gerold K, et al. Clinicopathological heterogeneity in the classification of mild head injury. Neurosurgery. 1996; 38(2): 245-250, doi: 10.1097/00006123-199602000-00002, indexed in Pubmed: 8869050.

6. Yüceer N, Mertol T, Arda MN. Kafa travmalı 106 çocuk olgunun klinik değerlendirme sonuçları. Düşünen Adam. 2005; 18: 95-100.

7. Astrand R, Rosenlund C, Undén J, et al. Scandinavian Neurotrauma Committee (SNC). Scandinavian guidelines for initial management of minor and moderate head trauma in children. BMC Med. 2016; 14: 33, doi: 10.1186/s12916-016-0574-x, indexed in Pubmed: 26888597.

8. Oliver T, Murray H. In minor head trauma, decision rules were sensitive for intracranial findings, but reductions in CT use varied. Ann Intern Med. 2018; 169(12): JC71, doi: 10.7326/ACPJC-2018-169-12-071, indexed in Pubmed: 30557424.

9. Cheng CY, Pan HY, Li CJ, et al. Physicians' Risk Tolerance and Head Computed Tomography Use for Pediatric Patients With Minor Head Injury. Pediatr Emerg Care. 2018 [Epub ahead of print], doi: 10.1097/ PEC.0000000000001540, indexed in Pubmed: 29847541.

10. Atmış A, Tolunay O, Çelik T, et al. Dilemma in Pediatric Head Trauma: Is Cranial Computed Tomography Necessary or Not in Minor Head Traumas? Turkish Journal of Pediatric Emergency and Intensive Care Medicine. 2016; 3(1): 27-31, doi: 10.4274/cayd.03164.

11. Lee C. Computed Tomography for Minor Head Injury. Oxford Medicine Online. 2016, doi: 10.1093/med/9780190223700.003.0001.

12. Akdur 0. Acil Servise Göz Travması Nedeniyle Başvuran Olguların Değerlendirilmesi. Akademik Acil Tıp Dergisi. 2009, doi: 10.4170/ jaem.2009.97759. 
13. Gardner J, Sexton KW, Taylor J, et al. Defining severe traumatic brain injury readmission rates and reasons in a rural state. Trauma Surg Acute Care Open. 2018; 3(1): e000186, doi: 10.1136/tsaco-2018-000186, indexed in Pubmed: 30234165.

14. Louis M, Trost J, Hollier L. Pediatric Skull Fractures. Facial Trauma Surgery. 2020: 285-290, doi: 10.1016/b978-0-323-49755-8.00030-x.

15. Varshneya K, Rodrigues AJ, Medress ZA, et al. Risks, costs, and outcomes of cerebrospinal fluid leaks after pediatric skull fractures: a MarketScan analysis between 2007 and 2015. Neurosurg Focus. 2019; 47(5): E10, doi: 10.3171/2019.8.FOCUS19543, indexed in Pubmed: 31675705.

16. Bouida W, Marghli S, Souissi S, et al. Prediction value of the Canadian CT head rule and the New Orleans criteria for positive head CT scan and acute neurosurgical procedures in minor head trauma: a multicenter external validation study. Ann Emerg Med. 2013; 61(5): 521-527, doi: 10.1016/j.annemergmed.2012.07.016, indexed in Pubmed: 22921164.

17. Borland ML, Dalziel SR, Phillips N, et al. Paediatric Research in Emergency Department International Collaborative group. Vomiting With Head Trauma and Risk of Traumatic Brain Injury. Pediatrics. 2018; 141(4), doi: 10.1542/peds.2017-3123, indexed in Pubmed: 29599113.

18. Çoban E, Şen GŞ, Güneysel Ö. Minör kafa travmalarında anormal kranial bilgisayarlı tomografi saptamada yüksek risk faktörlerinin belirlenmesi. Marmara Medical Journal. 2015; 28(1): 027, doi: 10.5472/ mmj.2015.03555.2.
19. Borland ML, Dalziel SR, Phillips N, et al. Paediatric Research in Emergency Department International Collaborative group. Vomiting With Head Trauma and Risk of Traumatic Brain Injury. Pediatrics. 2018; 141(4), doi: 10.1542/peds.2017-3123, indexed in Pubmed: 29599113.

20. Burstein B, Upton J, Terra HF, et al. UTILIZATION OF COMPUTED TOMOGRAPHY FOR PEDIATRIC HEAD TRAUMA FROM 2007-2014 IN THE UNITED STATES: BEFORE AND AFTER PECARN CLINICAL DECISION RULES. Paediatrics \& Child Health. 2018; 23(suppl_1): e8-e8, doi: 10.1093/pch/pxy054.020.

21. Dubb S, Agar S, Shah J, et al. CT Scan Consideration for Occult Skull Fracture in Paediatric Head Trauma. British Journal of Oral and Maxillofacial Surgery. 2019; 57(10): e73, doi: 10.1016/j.bjoms.2019.10.218.

22. Olivecrona Z, Undén J. Adult and Pediatric Mild and Moderate Head Injury Management in Scandinavian Countries. Neurotrauma. 2018: 123-128, doi: 10.1093/med/9780190279431.003.0011.

23. Shaikh H, Wrotniak BH, Mazur PM, et al. Women and Children s Hospital of Buffalo. Occult Head Injury in Children Less Than 2 Years With Suspected Child Abuse in the Emergency Department. Pediatr Emerg Care. 2019; 35(9): 596-599, doi: 10.1097/PEC.0000000000001187, indexed in Pubmed: 28562465.

24. Jalalvandi F, Arasteh $P$, Safari Faramani $R$, et al. Epidemiology of Pediatric Trauma and Its Patterns in Western Iran: A Hospital Based Experience. Glob J Health Sci. 2015; 8(6): 139-146, doi: 10.5539/ gjhs.v8n6p139, indexed in Pubmed: 26755468. 